\title{
Miniaturization of Bow Shaped Microstrip Antenna using Different Substrate
}

\author{
Manoj Kr. Dahiya \\ Deptt. of Elect.\& \\ Comm \\ Hindu College of \\ Engineering Sonipat, \\ India
}

\author{
Ritu Goel \\ Deptt. of Elect.\& \\ Comm., \\ Hindu College of \\ Engineering \\ Sonipat, India
}

\author{
Deppender \\ Dabas \\ A.P, Deptt. of Elect.\& \\ Comm. \\ PIET, Panipat
}

\author{
Rakesh Verma \\ Deptt. of Elect.\& \\ Comm., \\ Hindu College of \\ Engineering \\ Sonipat, India
}

\begin{abstract}
In recent era, the development in communication system requires development of small size electronic system .Now a days, there is demand of small size \& low cost microstrip antenna. Microstrip antenna is widely used in wireless communication Applications. Microstrip antenna has small size, low cost, easy in construction \& provides high performance over wide band of frequencies. In this paper, we are proposing a new approach for designing a very small size bow shapedmicrostrip antenna. This antenna is used to transmit \& receive radio signal at resonant frequency of 3 $\mathrm{GHz}$. At resonant frequency of $3 \mathrm{GHz}$, the antenna concentrates energy through a direction to give a better radiative performance. This antenna is design on different substrate such as roger 5880, roger 5870, benzocyclobuten, epoxy. The effect of these substrates on microstrip antenna is studied \& roger 5880 found to be a good substrate to design bow shaped microstrip antenna.
\end{abstract}

\section{Keywords}

Microstrip antenna, Resonant frequency, Roger 5870, Roger 5880, Benzocyclobuten, Epoxy.

\section{INTRODUCTION}

In wireless communication system, microstrip antenna has wide range of application in spacecraft,satellite,missile application etc. A microstrip antenna have attractive features such as light weight, low volume, low cost, easy to fabricate \& easy in construction[1]. A microstrip antenna have capability to provide better performance of radiation. A microstrip antenna has good gain as compared to other antenna because of its ability to concentrate of energy into a tight beam (expressed as narrow beam width) through a direction to provide better performance of radiation [3].

\subsection{Basic microstrip antenna}

A microstrip antenna is consist of a very thin metallic patch fabricated on dielectric substrate above a conducting ground plane[1]. The metallic patch or radiating patch is made of $\mathrm{Cu}$ (copper) \& Au (gold) [2]. Microsrtip antenna having different shape like rectangular, circular, triangular, elliptical, ring, disk, square or some other shape. Rectangular\& Circular microsrtipantenna are widely used in communication. These microstripantenna have same similarities as these cover a range of frequency from $100 \mathrm{MHz}$ to $100 \mathrm{GHz}$.
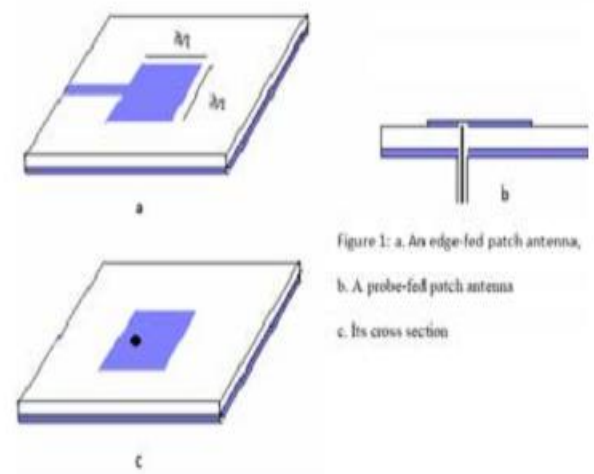
b. A proberefes potch antenas c. fis aoss section

Fig. 1 Mirostrip Patch antenna construction using microstrip fabrication techniques

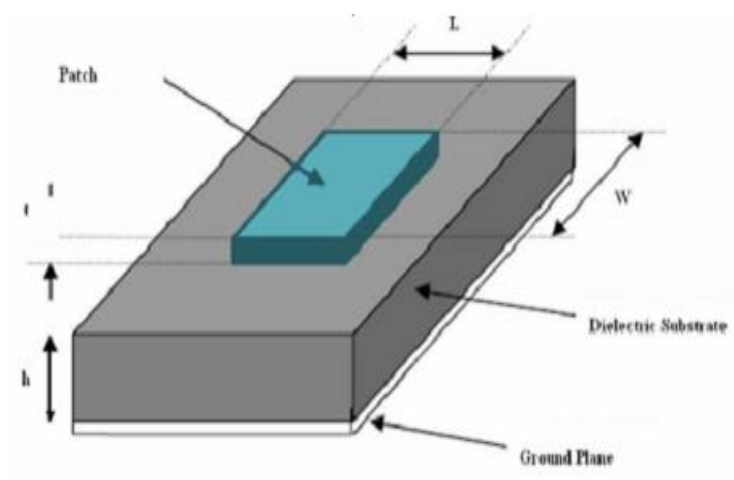

Fig. 2 Constructional view of rectangular microstrip antenna

A microstrip antenna has some disadvantages such as low efficiency, low power, large loss, and poor performances. The losses may be reduced by reducing thickness of substrate. Microstrip patch antenna has various methods of feed lines. A microsrtip antenna having dielectric substrate on one side\& patch on other side[2]. The methods of feed line to microstrip patch antenna are microstrip line, coplanar wave guide feed, coaxial probe \& proximity coupling[7]. 


\subsubsection{Substrates}

Substrate plays a very important role in designing a microstrip antenna. To design an antenna, it is very important to choose a suitable substrate. A substrate is consisting of dielectric material which affects the electrical performance of antenna \& transmission line[7]. The size of antenna is depend on dielectric constant of substrate. Generally, high microstrip antenna is used to reduce size of antenna. Some of substrate are ceramic substrates, semiconductor substrates, ferromagnetic substrates ( $\epsilon=9$ to 16$)$ \& composite material subatrates ( $\epsilon=2$ to 6 ). Some cermaic substrates have high dielectric constant $(E)$ in range 20 to 150 . Semiconductor substrates are of $\operatorname{Si}(\epsilon=11.9) \& \operatorname{GaAs}(\epsilon=13.0)$.

In this paper, we are giving a direction towards the fabrication on different composite material substrate like roger 5870, roger 5880, benzocyclobuten\& Epoxy having dielectric constant $2.2,2.33,2.6 \& 3.6$ respectively \& effect of these material on resonant frequency of microstrip antenna is studied..

\section{DESIGN OF BOW-SHAPE MICROSTRIP ANTENNA}

For design of bow- shape microsrtip antenna, following parameter are taken

$\mathrm{h}=1 \mathrm{~mm}, \mathrm{~W}=21 \mathrm{~mm}, \mathrm{~L}=25 \mathrm{~mm}, \mathrm{Wcd}=\mathrm{Wcp}=1 \mathrm{~mm}$,

$\mathrm{S} 1=30.7 \mathrm{~mm}, \mathrm{D}=28.8 \mathrm{~mm}, \mathrm{Lo}=6.6 \mathrm{~mm}$, Wo $=1 \mathrm{~mm}$

$\mathrm{h}=$ height of patch

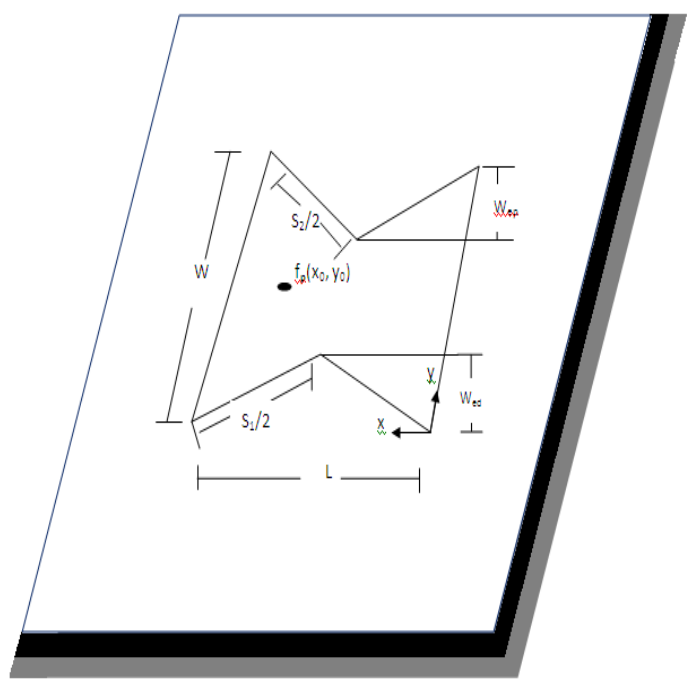

Fig. 3 Constructional view of bow-shaped microstrip antenna

The geometry of the new compact microstrip antenna

$\mathrm{W}=$ width of patch

$\mathrm{L}=$ length of patch antenna

$\mathrm{S} 1$ = slant height of antenna

$\mathrm{D}=$ diameter of antenna

$\epsilon=$ Dielectric constant of substrate

$\mathrm{C}=$ speed of light $=3 \times 108 \mathrm{~m} / \mathrm{s}$

$\varepsilon 1=$ effective dielectric constant

Seff=effective slant height of antenna

\section{CALCULATION OF RESONANT FREQUENCY}

The bow shapemicrostrip antenna is operated in basic TM10 mode and coaxial feed line are used. The resonant frequency $\left(f_{10}\right)$ for TM10 mode is calculated by formula given below.

$$
\begin{gathered}
f_{10}=\frac{c}{2\left(S_{\text {eff }}+2 \Delta l_{1}\right) \sqrt{\varepsilon_{1}}} \\
\varepsilon_{1}=\frac{\varepsilon_{r}+1}{2}+\frac{\varepsilon_{r}-1}{2}(1+12 h / W)^{-1 / 2} \\
\Delta l_{1}=\frac{0.412 h\left(\varepsilon_{1}+0.3\right)(W / h+0.258)}{\left(\varepsilon_{1}-0.258\right)(W / h+0.8)}
\end{gathered}
$$

$$
\begin{aligned}
& \text { For }(L>=W) \\
& \begin{aligned}
S_{e f f} & =S_{1}+2.3(L-2 W-0.0046 / L) W_{c d} \\
& +0.00006 / L-0.1\left(W_{c p}-0.01\right) \quad \text { for } W_{c d} / W<1
\end{aligned}
\end{aligned}
$$

\section{EFFECT OF DIFFERENT SUBSTRATE ON RESOSNANT FREQUENCY OF ANTENNA}

Bow shape microsrtip antenna having height $=1 \mathrm{~mm}$, length $=25 \mathrm{~mm} \&$ width $=21 \mathrm{~mm}$, slant height $=30.7 \mathrm{~mm}$ is taken \& effect of different material Roger RT 5870, Roger 5870, Benzocyclobuten\& Epoxy with dielectric permittivity of 2.2, $2.33,2.6 \& 3.6$ is studied \& resonant frequency is calculated as shown in table

\begin{tabular}{|c|c|c|}
\hline Substrate Material & $\begin{array}{c}\text { Dielectric } \\
\text { Permittivity ( } \\
\varepsilon \mathrm{r} \text { ) }\end{array}$ & $\begin{array}{c}\text { Resonant } \\
\text { Frequency(f10) } \\
\text { GHz }\end{array}$ \\
\hline $\begin{array}{c}\text { Roger RT 5880 } \\
\text { Droid }\end{array}$ & 2.2 & 3.00 \\
\hline Roger 5870 & 2.33 & 2.92 \\
\hline Benzocyclobuten & 2.6 & 2.78 \\
\hline Epoxy & 3.6 & 2.38 \\
\hline
\end{tabular}

\section{CONCLUSION}

In this paper we proposes a new approach to design microstrip antenna having following benefits:

1. Bow shape mirostrip antenna with substrate Roger 5880 having highest Resonance frequency $3 \mathrm{GHz}$ as compared to other substrate microstrip antenna \& size of antenna is too small. Hence Roager 5880 is good material for better performance of bow shaped antenna. 
2. The proposed result is compared to a rectangular patch microstrip antenna with the same dimensions and substrate.It is found that Bow shaped antenna gives higher value of resonant frequency than a rectangular patch microstrip antenna.

3. The overall area of the microstrip antenna is reduced greater than $65 \%$ for $\mathrm{TM}_{10}$ mode frequency as compare to a rectangular patch microstrip antenna

\section{REFERENCES}

[1] Jagtar Singh, A.P Singh, T.S. Kamal, "On the Design of Triangular Microstrip Antenna for Wireless Communication", International Journal of Computer Applications-IJCA , Feb. 2012.

[2] T.Durga Prasad, K. V. Satya Kumar, MD KhwajaMuinuddin, Chisti B. Kanthamma, V.Santoshkumar, "Comparisons of Circular and Rectangular Microstrip Patch Antennas", International journal of Communication Engineering ApplicationsIJCEA,Vol 02, Issue 04, July 2011.

[3] D.Rakesh, P.RakeshKumar,Prof. Habibullakhan,KCh Sri Kavya, B.T.P.Madhav, K,Prabhu Kumar, S BalaDurga Prasad, "Performance Evaluation of Microstrip Square Patch Antenna on Different Substrate Materials", Journal of Theoretical and Applied Information Technology, 30th April 2011

[4] P.N. Misra, "Planar Rectangular Microstrip Antenna for Dualband Operation", IJCST, Vol. 2, Issue 3, September 2011

[5] .Kumar Ashok, Singh Pushpendra, D.Sunita, "Analysis and Applications of Microstrip Antennas Having Magnetic Materials", 1st International Conference on
Innovations and Advancements in Information and Communication Technology-ICIAICT 2012.

[6] M. Paulson, S.O. Kundukulam, C.K. Aanandan ,P. Mohanan, "Resonance Frequencies of Compact Microstrip Antenna", Electronic Letter, 13th september 2001, Vol. 37, No. 19.

[7] Ramesh Garg, PrakashBhartia, InderBahl, ApisakIttipiboon, "Microstrip Antenna Design Handbook",2001.

[8] C. A. Balanis, Antenna Theory, John Wiley \& Sons, Inc., 1997.

[9] K.D.Parsad Antenna and Wave Propagation,Satya Parkashan,2005.

[10] I.J. Bahal and P. Bhartia, Microstripantennas,Artecch House,Dedham,MA, 1980

[11] R.Malmathanraj, S. ThamraniSlevi, "Artificial neural networks in parameter optimization of rectangular microstrip antenna,"

[12] Rajeev Wakodkar et al, "Neurocomputational analysis of square microstrip antenna characteristics,"IJECT Vol.1, Dec.2010.

[13] Kin-Lu Wong, Compact and Broadband Microstrip Antennas, Jon Wiley \& Sons, Inc.,2002

[14] J. R. James, P. S. Hall, and C. Wood, Microstrip Antenna Theory and Design, Peter Perigrinus,London, 1981.

[15] Sanad, M. "A Small Size Microstrip Antenna Having a Partial Short Circuit" IEEE International Conference on Antenna and Propagation, vol. 1, pp.465-471, April 1995

[16] J. R. James and P. S. Hall, Handbook of Microstrip Antennas, Peter PerigrinusLtd.,London, 1989. 